\title{
Análise do comportamento e população LGBT: revisão das produções de pós-graduação no Brasil
}

\section{Behavior analysis and LGBT population: review of the graduate productions in Brazil}

\section{Análisis conductual y poblácion LBGT: revisión de las producciones de la posgraduación en Brasil}

\author{
Leandro Herkert Fazzano1, Igor Marçal Mena², Thainã Eloá Silva Dionísio ${ }^{3}$ Alex Eduardo Gallo4
}

[1] [3] [4] Universidade Estadual de Londrina [2] Universidade Federal do Mato Grosso do Sul I Título abreviado: Análise do comportamento e população LGBT: revisão das produções de pós-graduação no brasil I Endereço para correspondência: Leandro Herkert Fazzano. R. Prefeito Hugo Cabral, 1161. CEP- 86020-111 I Email: leandrofazzano@hotmail.com I doi: 10.18761/PAC.2020.v11.n1.05

\begin{abstract}
Resumo: As produções científicas sobre a população LGBT na Análise do Comportamento são poucas, conforme apontado em revisões da área. Todavia, não se é discorrido nestas revisões sobre a produção da pós-graduação nacional. Este artigo teve por objetivo elencar os estudos sobre a população LGBT nas pós-graduações Stricto Sensu de Psicologia, com base na análise do comportamento, sendo estas recuperadas através da disponibilidade nos bancos de dissertações de todos os programas. Foram recuperadas oito produções, todas dissertações de mestrado, sendo analisadas cinco destas, e caracterizadas em relação ao ano, a instituição, a temática e a estrutura. Observa-se o aumento gradual das produções na última década, porém, não se constituindo em um campo consolidado, sendo o principal foco das dissertações a LGBTfobia. São discutidos pontos em comum entre elas, como a ausência de visão patologizante, e também alguns problemas metodológicos das mesmas. Espera-se que as produções nesta temática continuem crescendo, sendo apontada a necessidade de mais estudos em diferentes "recortes" da temática.
\end{abstract}

Palavras-chave: Análise do Comportamento; LGBT; Pós-Graduação 
Abstract: Behavior Analysis scientific production about LGBT community is low considering published reviews. However, they do not discuss on those review the post-graduation production. This paper aimed at listing national studies about LGBT community done on psychology post-graduation programs based on behavior analysis approach, retrieved from programs data base. We retrieved eight publications, all master thesis, and analyzed five, categorizing about publication year, institution, thematic and structure. We can observe a gradual increasing on publication on last decade, however, it is not a consolidate field, and major focus was on LGBTphobia. We discuss common points as absence of pathologic view and some methodological limitations. We hope publications continue increasing and more studies on different cutouts of this thematic.

Keywords: Behavior Analysis, LGBT; Graduation

Resumen: Hay pocas producciones científicas sobre la población LGBT en la Análisis Conductual, como se señala en las revisiones de área. Todavia, no se discute sobre la producción de posgrado. Este artículo tiene como objetivo señalar las producciones nacionales sobre la población LGBT en los estudios de posgrado de Psicología Stricto Sensu, basados en Análisis Conductual, que se recuperan mediante la disponibilidad de disertaciones en todos los programas. Se recuperaron ocho producciones, todas disertaciones de maestría, se analizaron cinco de ellas y se caracterizaron en relación con año, la institución, el tema y la estructura. Hay un aumento gradual de las producciones en la última década, sin embargo, no constituye un campo consolidado, siendo el foco principal de las disertaciones LGBTfobia. Se discuten puntos comunes entre ellos, como la ausencia de visión patologizante, y también algunos problemas metodológicos de la misma. Se espera que las producciones sobre este tema continúen creciendo, señalando la necesidad de más estudios en diferentes "recortes" del tema.

Palabras clave: Análisis Conductual; LGBT; Posgraduación 


\section{Introdução}

Por ser uma ciência cujo objeto de estudos é a interação entre organismo e ambiente no qual aquele está inserido (Skinner, 1953/2003), a Análise do Comportamento abrange uma ampla possibilidade como campo de estudo. Partindo de sua compreensão de comportamento, esta abordagem compreende que os fenômenos, outrora ditos "psíquicos", ocorrem em função do ambiente físico, social e cultural. (Skinner, 1990).

Um destes fenômenos possíveis de serem estudos pela Análise do Comportamento é a Diversidade Sexual. Esse termo, embora popular, é tradicionalmente compreendido envolvendo os conceito de Sexo, Gênero, Orientação Sexual e Expressão de Gênero pelas quais cada indivíduo se reconhece (Brasil, 2018). Nesse sentido, a compreensão de "sexo" diz respeito ao biológico, as diferenças cromossômicas, anatômicas e fisiológicas entre os indivíduos, usualmente separados em macho e fêmea (Butler, McKie \& Ratcliffe, 1990; Brasil, 2018).

A noção de gênero se dá mediante as relações sociais estabelecidas entre os sexos (Scott 1986; Saffioti, 2004). Nesse sentido, o termo "gênero" diz respeito à uma interpretação cultural do sexo, partindo de características biológicas atreladas a construção social imposta de classes de comportamentos específicos de populações em uma dada cultura (Scott 1986; Ruiz, 2003; Saffioti, 2004).

Assim, ao se falar em gênero, também se faz necessário entender identidade de gênero e expressão de gênero. A Identidade de Gênero se refere a como o indivíduo percebe a si mesmo independente de seu sexo biológico (Bento, 2006; Pedrosa, 2009), sendo os indivíduos que se identificam com o gênero socialmente imposto chamados de cisgênero, enquanto os que não se identificam com o gênero socialmente imposto denominados de transgênero. Já a Expressão de Gênero é a forma com que indivíduos se vestem, interagem socialmente e emitem diversas classes de comportamentos dentro de estereotipias tidas como masculinas ou femininas conforme as normas culturais, que pode ou não estar em consonância com o sexo biológico ou identidade de gênero (Brasil, 2018). É válido ressaltar que tanto a percepção e identificação de si quanto a forma com que são expressa, são construídas através da história de reforçamento do indivíduo (Mallot, 1996).

Orientação sexual diz respeito à atração afetivo-sexual, a qual é selecionada no repertório do indivíduo, considerando-se variáveis filogenéticas, ontogenéticas e culturais (Mallot, 1996; Mizael, 2018). Tal noção também já foi exposta por Kinsey, Pomeroy e Martin (1948), ao exporem que o comportamento sexual humano é complexo, e que seu estudo não pode ser separado de profunda análise cultural, levando em conta aspectos como política, jurisdição e religiosidade das sociedades.

Além das questões identitárias acima citadas, o campo da diversidade sexual também está marcado por temas pertinentes a vivência dos indivíduos, sobretudo das populações não heteroafetivas (lésbicas, gays e biafetivos) e das populações "trans" (transexuais, transgêneros e travestis). A violência sofrida por estas populações, os modelos de relacionamento afetivo, questões relacionadas a saúde e políticas públicas são algumas das temáticas que perpassam este campo de estudos. Portanto, é possível notar que esta temática se constitui em uma vasta área de conteúdo, composta desde pesquisas a respeito de determinantes biológicos (Coppen, 1959; Davison, Brierley, \& Smith, 1971), determinantes sociais (Paul, 1993) até fenômenos sociais mais complexos, como a violência e a própria cultura. Cabe, então, compreender melhor a respeito da produção da Análise do Comportamento sobre este campo de estudos.

Um primeiro estudo a caracterizar a área é o de Carvalho, Silveira e Dittrich (2011). Os autores realizaram uma revisão da literatura analítico comportamental no periódico Journal of Applied Behavior Analysis (JABA) com o objetivo de levantar os artigos que tratam da temática "homossexualidade". Foram recuperados 10 artigos que atenderam os critérios de inclusão, publicados entre 1968 a 2010. Em suma, cinco dos artigos indicavam técnicas que tinham como objetivo a reversão do comportamento homossexual e/ou transexual, na medida em que os demais apresentam críticas a respeito deste procedimento.

Mizael (2018) elaborou uma segunda revisão da literatura. Foram pesquisados 13 periódicos, nacionais e internacionais, responsáveis por publicações analítico-comportamentais, recuperadas as publicações que apresentavam a temática "homos- 
sexualidade" como central e sem uma visão patologizante, resultando em três artigos. Por ter recuperado poucos estudos, a autora incluiu na busca o Scientific Eletronic Library Online (SCIELO), utilizando os mesmos descritores com o acréscimo do termo "análise do comportamento", resultando em mais um artigo recuperado, totalizando quatro artigos. Após descrevê-los, a autora aponta pouca produção nacional sobre a temática LGBT em Análise do Comportamento e a necessidade da realização de mais estudos.

Uma revisão mais específica sobre a violência contra homossexuais foi realizada por Fazzano e Gallo (2015). Os autores procuraram em bases de dados de periódicos nacionais e internacionais por publicações a respeito de homofobia, relatando que as produções recuperadas apresentavam causas "mentalistas", em especial pautadas no modelo psicodinâmico, compreendendo a homofobia enquanto uma homossexualidade latente expressa pelo agressor, ou defesa egóica, não sendo encontradas produções com base analítico comportamental. Assim, os autores elaboram uma compreensão do comportamento homofóbico a partir do escopo teórico da Análise do Comportamento.

Desta forma, seria possível afirmar, pelo descrito por Carvalho, Silveira e Dittrich (2011), Fazzano e Gallo (2015) e Mizael (2018), que a produção da Análise do Comportamento, internacional e principalmente nacional, pouco tem-se dedicado à temática $\mathrm{LGBT}^{1}$. Porém, antes de conduzir a esta conclusão, torna-se importante ressaltar que a busca realizada pelos autores nestes estudos foi apenas com artigos publicados, não contemplando a produção científica de programas Stricto Sensu de pós-graduação.

Deste modo, o objetivo deste estudo se configura a partir do levantamento da produção analítico-comportamental a respeito da temática LGBT em programas de pós-graduação Stricto Sensu no

1 Neste trabalho optou-se pelo uso do acrônimo LGBT como referência à minorias sexuais e de gênero, pois, como aponta Fernandes (2018), este é o acrônimo que melhor representa o contexto brasileiro, estando também em conformidade com documentos oficiais (Brasil, 2013; 2018). Ademais, a sigla "LGBT" é utilizada neste artigo sem perda de significado ou relevância para o mesmo, dado a sua abrangência em contemplar diversas orientações sexuais e identidades de gênero.
Brasil. Espera-se que, a partir deste estudo, possa-se ter maior observância e compreensão sobre a produção da Análise do Comportamento a respeito da população LGBT.

\section{Método}

O presente trabalho trata-se de uma revisão sistemática da produção de pós-graduações sobre temáticas referentes à população LGBT que utilizam a Análise do Comportamento como referencial teórico. Para tal, foram selecionados todos os programas de pós-graduação Stricto Sensu na área de Psicologia das universidade brasileiras, conforme indicado pela plataforma SUCUPIRA. No total, foram consultados 160 programas entre mestrado e doutorado. Os pesquisadores entraram na página de cada um dos programas, acessando todas as teses e dissertações disponíveis.

Foram utilizados para a busca os seguintes termos: LGBT; homofobia, Lgbtfobia; homoafetividade; orientação sexual e identidade de gênero. Estes termos foram utilizados devido a abrangência dos mesmos, sendo as especificidades de cada população já abarcada nos termos. Por tratar-se apenas de programas nacionais, os descritores utilizados foram apenas em português, não havendo combinação de palavras.

As buscas foram realizadas entre agosto de 2019 à novembro de 2019, não sendo aplicada restrição de datas de publicação, para que a maior quantidade de dissertações e teses possível fosse localizada dentro da temática LGBT. Vale destacar que o levantamento das publicações de pós-graduação deu-se pela disponibilidade online das mesmas. É possível, neste sentido, que algumas produções não se encontrem disponíveis online, não sendo englobadas nesta revisão.

Apenas as produções focadas em analisar ou descrever fenômenos que envolvem a temática LGBT foram analisadas, sendo descartadas as produções recuperadas que não possuíam este foco ou apenas faziam menção a qualquer um dos termos utilizados na busca. Após a leitura das produções na íntegra, as pesquisas foram caracterizadas enquanto ano de produção, programa no qual foi realizada, a temática específica do trabalho e estrutura da produção, todas descritas abaixo. 


\section{Resultados}

Foram encontradas apenas oito produções de pós-graduação strictu senso a partir dos descritores utilizados. Observou-se que três das produções recuperadas não contemplavam os critérios de inclusão da pesquisa (Oliveira, 2006; Vieira, 2007; Corrêa, 2011). Tais produções apareceram nos resultados das buscas por citarem, ao longo das dissertações, algum dos descritores selecionados, entretanto, após leitura integral dos trabalhos, foi constatado que duas destas (Oliveira, 2006; Corrêa, 2011) apenas apresentavam os termos, não versando sobre a temática LGBT, enquanto que Vieira (2007) parte da psicologia evolutiva, não utilizando o escopo da Análise do Comportamento. As produções recuperadas totalizam cinco, todas referentes a dissertações de conclusão de mestrado, sendo elas: Menezes (2005); Fazzano (2014); Devides (2018); Lima Neto (2019) e Teixeira (2019), como exibido na Quadro 1.

Em relação às instituições em que as pesquisas foram desenvolvidas, observa-se que estas se concentram em quatro universidades: duas produções da Universidade Estadual de Londrina (UEL); uma na Universidade Federal do Pará (UFPA); uma da Pontifícia Universidade Católica de São Paulo
(PUC-SP); e uma na Universidade Estadual Paulista (UNESP-Bauru). Assim, a distribuição dos autores em relação a universidade é: UEL, Fazzano (2014) e Devides (2018); UFPA, Menezes (2005); PUC-SP, Lima Neto (2019) e; UNESP-Bauru, Teixeira (2019).

É possível notar um crescente aumento no número de produções sobre a temática, sobretudo na última década. Durante o período de 2000 à 2009, registra-se apenas uma dissertação sobre a temática (Menezes, 2005); sendo as outras 4 compreendidas entre 2010 a 2019 (Fazzano, 2014; Devides, 2018; Lima Neto, 2019; Teixeira, 2019).

Sobre o foco dado nas dissertações, é possível observar que estas perpassam diversos assuntos relacionados à temática LGBT. Menezes (2005) trabalhou com o levantamento dos possíveis determinantes do comportamento homossexual, enquanto Lima Neto (2019) aborda a temática de HIV/AIDS e Teixeira (2019) foca em analisar projetos de leis sobre a criminalização da LGBTfobia. As produções de Fazzano (2014) e Devides (2018) são as únicas que podem ser agrupadas em torno da temática da violência contra a população LGBT, embora cada um dos autores tenha discorrido sobre populações diferentes. A seguir, será feito uma breve descrição das produções.

\section{Quadro 1 - Dissertações recuperadas e analisadas}

\begin{tabular}{|c|c|c|c|c|}
\hline Autor (Ano) & Instituição & Orientador(a) & Título & Palavras-chaves \\
\hline Menezes (2005) & UFPA & $\begin{array}{l}\text { Marcus Bentes de } \\
\text { Carvalho Neto }\end{array}$ & $\begin{array}{l}\text { Análise da investigação dos } \\
\text { determinantes do comporta- } \\
\text { mento homossexual humano }\end{array}$ & $\begin{array}{l}\text { Inato versus aprendido; comporta- } \\
\text { mento homossexual; determinação } \\
\text { do comportamento; sexualidade }\end{array}$ \\
\hline Fazzano (2014) & UEL & Alex Eduardo Gallo & $\begin{array}{l}\text { Análise do fenômeno da } \\
\text { homofobia: Identificando } \\
\text { contingências envolvidas }\end{array}$ & $\begin{array}{l}\text { Homofobia; Análise do } \\
\text { Comportamento; Violência; } \\
\text { Preconceito; Contingências; }\end{array}$ \\
\hline Devides (2018) & UEL & Alex Eduardo Gallo & $\begin{array}{l}\text { A violência contra travestis e } \\
\text { transexuais mulheres a partir } \\
\text { de uma perspectiva analítico- } \\
\text {-comportamental }\end{array}$ & $\begin{array}{l}\text { Sexualidade,Transexualidade, Análise } \\
\text { do Comportamento, Cultura,Violência } \\
\text { de gênero. }\end{array}$ \\
\hline Lima Neto (2019) & PUC-SP & $\begin{array}{l}\text { Maria do Carmo } \\
\text { Guedes }\end{array}$ & $\begin{array}{l}\text { Riscos, vulnerabilidade e } \\
\text { HIV/Aids entre homens que } \\
\text { fazem sexo com homens: } \\
\text { uma análise verbal }\end{array}$ & $\begin{array}{l}\text { HIV/Aids, Comportamento Verbal, } \\
\text { Comportamento Governado por } \\
\text { Regras, Risco, Homens que fa- } \\
\text { zem sexo com homens, Análise } \\
\text { Comportamental do Discurso (ACD) }\end{array}$ \\
\hline Teixeira (2019) & $\begin{array}{l}\text { UNESP } \\
\text {-Bauru }\end{array}$ & $\begin{array}{l}\text { Ana Claudia } \\
\text { Bortolozzi Maia }\end{array}$ & $\begin{array}{l}\text { Criminalização da LGBTfobia: } \\
\text { Uma análise comportamental } \\
\text { de projetos de lei }\end{array}$ & $\begin{array}{l}\text { LGBTfobia, Sexualidade, Análise do } \\
\text { Comportamento, Políticas Públicas }\end{array}$ \\
\hline
\end{tabular}


O trabalho de Menezes (2005) descreve produções acadêmicas sobre os determinantes do comportamento sexual humano, com foco na homossexualidade. A metodologia utilizada foi levantamento bibliográfico de trabalhos sobre determinantes do comportamento homossexual humano, com posterior organização destes e discussão dos resultados obtidos. O trabalho foi dividido em 12 capítulos, agrupados pela autora em três grandes vieses: do primeiro ao quarto capítulo, a autora discorre sobre os debates acerca da determinação biológica do comportamento sexual humano e elenca algumas metodologias científicas utilizadas nestas discussões; do capítulo quinto ao capítulo décimo são apresentados tanto a metodologia do trabalho da autora, quanto estudos empíricos que buscavam encontrar possíveis determinantes endócrinos, genéticos e cerebrais do comportamento homossexual humano; e os dois últimos capítulos discutem sobre possíveis contingências ambientais que atuam na manutenção e seleção destes comportamento, em conjunto com características filogenéticas, assim como implicações éticas das pesquisas sobre determinantes da sexualidade humana.

A dissertação de Fazzano (2014), intitulada "Análise do fenômeno da homofobia: identificando contingências envolvidas", tem como temática central a violência contra pessoas LGBT. A pesquisa realizada pelo autor teve como objetivo elencar variáveis ambientais que estariam envolvidas em agressões contra pessoas homossexuais. Nesse sentido, Fazzano (2014) realizou pesquisa quantitativa e qualitativa, dividida em duas fases, sendo a primeira fase a aplicação de questionários com 73 universitários autodeclarados como LGBT, e a segunda fase, a realização de entrevistas com sete participantes, com a finalidade de estabelecer hipóteses funcionais sobre as agressões sofridas. Sua dissertação está dividida em quatro capítulos, sendo eles: 1) "Heteronormatividade na visão da Análise do Comportamento: História, Normalidade e Cultura", no qual o autor busca apresentar uma possível explicação sobre heteronormatividade como prática cultural e como esta poderia estar relacionada a homofobia; 2) "Uma análise da homofobia sob a perspectiva da Análise do Comportamento", capítulo no qual o autor apresenta definições sobre a conceituação de homofobia e descrições molecu- lares dos episódios de violência; 3) "Levantamento em episódios homofóbicos: estabelecendo possíveis variáveis", apresentando os resultados estatísticos da coleta com os questionários, sinalizando a maior ocorrência de violência em alguns ambientes, a ausência de denúncias e a presença de comportamento de fuga e esquiva das vítimas e; 4) "Hipóteses funcionais sobre agressões homofóbicas: Relatos de experiência vivida", capítulo no qual o autor apresenta hipóteses funcionais das entrevistas realizadas.

Ainda na temática da violência, Devides (2018) aborda agressões cometidas contra mulheres transsexuais e travestis. Seu trabalho intitulado "A violência contra travestis e transexuais mulheres a partir de uma perspectiva analítico comportamental" foi apresentado no formato de dois artigos, cada um com um objetivo particular dentro da temática. No primeiro artigo, "Uma interpretação analítico-comportamental sobre o processo de construção da identidade trans", a autora discorre sobre o conceito de gênero na sociedade, como este afeta o desenvolvimento dos indivíduos trans desde a infância e colaboram com a perpetuação de violências cometidas. $\mathrm{O}$ segundo artigo, intitulado "Análise de relatos de violência contra travestis e transexuais mulheres a partir de uma perspectiva analítico-comportamental" se trata de uma análise do conteúdo de relatos de quatro mulheres transsexuais e travestis, sob o olhar da análise do comportamento, elucidando contingências mantenedoras da violência contra esta população.

Lima Neto (2019) buscou esquematizar as concepções a respeito do HIV/Aids de homens que praticam relações homossexuais (HSH), mas não necessariamente se identificam enquanto homossexuais. Sua dissertação é composta pela introdução, na qual o autor discorre como ocorreu a epidemia do HIV/Aids, os primeiros tratamentos, a disseminação do vírus no Brasil e o papel que o Governo assumiu. Na sequência, consta o referencial teórico, discorrendo sobre Comportamento Verbal e Comportamento Governado por Regras, o que o leva adotar a Análise Comportamental do Discurso (ACD) e elaborar o conceito Operante de Risco. No seu método, é apresentado o Questionário de Operantes Verbais sobre Comportamento Sexual: HSH, elaborado para ser utilizado na pesquisa. Sua coleta ocorreu com oito participantes, sendo os re- 
sultados apresentados, discutidos e agrupados em nove categorias: i) parcerias sexuais; ii) sorologia para o HIV e adesão ao tratamento antirretroviral; iii) uso do preservativo; iv) análise de risco; v) informações sobre HIV/Aids; vi) percepção de vulnerabilidade e estratégias de prevenção; vii) variáveis de controle de Operante de Risco e busca de parcerias sexuais; viii) possíveis variáveis para a relação sexual desprotegida e ix) juízos de valor.

A pesquisa realizada por Teixeira (2019), "Criminalização da LGBTfobia: Uma análise comportamental de Projetos de Lei", teve como objetivo analisar funcionalmente os Projetos de Leis propostos até o ano de 2017 que visavam a criminalização da LGBTfobia, e os Pareceres Legislativos que estes Projetos receberam. Para tal, o autor valeu-se de pesquisa em arquivos legislativos como metodologia de trabalho, propondo realizar análises de contingências comportamentais. Foram recuperados oito Projetos de Lei e catorze Pareceres Legislativos referentes a três dos Projetos de Lei - a partir do Portal da Câmara dos Deputados e Portal do Senado Federal -, dos quais a análise partiu da identificação dos Atores Alvos, Contextos Antecedentes, Comportamentos e Consequências. Em seus resultados, $\mathrm{o}$ autor aponta a ausência dos itens que compõem uma contingência, bem como a não especificação do que se é compreendido por orientação sexual, identidade de gênero e expressão de gênero; fatores que levam a não compreensão do que está sendo proposto e o que deveria ser criminalizado. $\mathrm{O}$ autor aponta que dos oito projetos, apenas um encontra-se mais próximo do ideal, ou seja, pautando-se nas categorias de análise do autor da dissertação.

\section{Discussão}

Foi observado que nenhuma das dissertações analisadas apresentam uma visão patologizante da homossexualidade, bissexualidade e da transexualidade. Nesse sentido, é possível afirmar que as produções da Análise do Comportamento na pós-graduação não consideram tais aspectos da sexualidade como sendo distúrbios ou doenças, corroborando com Mizael (2018), não focando na elaboração de técnicas que busquem reverter ou reorientar a sexualidade dos indivíduos. Ademais, é possível deduzir que a produção nacional, assim como apontado por Carvalho, Silveira e Dittrich (2011) por meio da retirada da homossexualidade da Classificação Internacional de Doenças em 1973, segue a tendência de não considerar como patológicas as orientações sexuais e identidades de gênero não cisheteronormativas, fator que vai de encontro com a decisão do Conselho Federal de Psicologia (1999; 2018) e Organização Mundial da Saúde (World Health Organization) (2018).

Atenção especial pode ser dada a produção de Menezes (2005) a qual apresenta vasta bibliografia de pesquisas voltadas para a compreensão em nível genético e fisiológico da homossexualidade, muitas sob o viés patologizante. Entretanto, a autora, embasada em outros trabalhos, argumenta que estudos mais antigos apresentavam menos rigor metodológico, questões antiéticas e respaldados em posicionamentos sociais acerca de moralidade, e não de descobertas científicas sobre comportamento humano. A autora apresenta que pesquisas mais recentes, com maior rigor metodológico e preocupadas com a ética em pesquisa, não concluem que a homossexualidade possa ser considerada como doença, mas sim que é parte constituinte da vida dos indivíduos.

Outro ponto a ser destacado nas dissertações analisadas é que, de forma geral, os estudos não discorrem especificamente sobre a população de lésbicas e pessoas bissexuais. Apesar de indivíduos LGBT sofrerem violências, populações específicas que compõem este acrônimo sofrem violências específicas e muitas vezes distintas entre si, o que é relatado no estudo de Devides (2018) com mulheres transsexuais e travestis. Uma possível hipótese para a ausência de aprofundamento sobre as populações de lésbicas e bissexuais é de que os estudos desta temática na análise do comportamento ainda são recentes, e uma base teórica ainda está sendo construída nessa área, acarretando em empecilho para maiores os estudos.

A respeito da metodologia utilizada nas pesquisas, o primeiro ponto analisado diz respeito à forma como a coleta de dados dos trabalhos foi realizada. Três dissertações (Fazzano, 2014; Devides, 2018; Lima Neto, 2019) apresentam análises realizadas a partir do relato verbal dos participantes. Os relatos verbais são analisados a partir da Análise do Comportamento e permite ao pesquisador ter aces- 
so à informações que não podem ser observadas diretamente, como por exemplo um episódio de violência sofrida a qual o pesquisador não estava presenciando no momento. Glenn (1989) ressalta que o comportamento verbal é selecionado e mantido por contingências como qualquer outro comportamento, e é fortemente controlado por contingências culturais, e com a interação com o ouvinte (Skinner 1957/1978).

O controle de variáveis em entrevistas é mais esparso do que em estudos laboratoriais, o que pode comprometer em parte a coleta de dados. Porém também há de se constar que muitos dos episódios apresentados nas entrevistas dos estudos não poderiam ser acessados de outras formas. A ainda pequena produção com a temática também pode ser uma variável relevante, haja vista que existe uma necessidade em descrever com maior clareza o fenômeno da violência contra indivíduos LGBT, e o relato verbal é uma fonte válida para que se tenha acesso à tais acontecimentos (Simonassi \& Cameschi, 2003).

Ainda referente a estas três dissertações, aponta-se que o número de participantes (n) entrevistados poderia ser considerado pequeno, sendo sete em Fazzano (2014), quatro em Devides (2018) e oito em Lima Neto (2019). Embora não esteja claro nas pesquisas, é possível hipotetizar que este baixo número de participantes pode ser devido a própria especificidade das populações pesquisadas. É provável que, dado o preconceito e as opressões vivenciadas cotidianamente pela população LGBT, os indivíduos sintam-se pouco à vontade em falar sobre suas vivências (sejam elas de violência ou da prática sexual), por vezes esquivando-se. Esta hipótese pode ser pensada sobretudo nos estudos de Fazzano (2014) e Devides (2018), que apontam para comportamentos de fuga e esquiva muito presentes no repertório dos participantes.

Vale ressaltar que essas pesquisas, de acordo com o descrito pelos autores, utilizam-se de entrevistas semi estruturadas, sendo executadas com o pesquisador e o participante, tendo o áudio gravado e transcrito. No caso de Lima Neto (2019), não é possível compreender, na leitura da dissertação, como a metodologia descrita foi executada em sua integralidade. Mais além, algumas das afirmações nos resultados apresentam-se de forma generaliza- das, o que talvez possa incorrer em erro, uma vez que sua amostra é apenas de oito participantes.

Considerando que duas das dissertações recuperadas abordam a violência sofrida pela população LGBT (Fazzano, 2014; Devides, 2018), e outra pode ser enquadrada na área da Saúde (Lima Neto, 2019), torna-se importante ressaltar que tais temas são transversais a Políticas Públicas. Nesse sentido, foi averiguado que nenhuma das produções recuperadas têm este foco. A dissertação mais próxima desta temática é a de Teixeira (2019), ao discorrer sobre Projetos de Lei (PLs) acerca da criminalização da LGBTfobia, baseando-se numa visão comportamental.

Desta forma, é possível inferir que o conteúdo discutido por Teixeira (2019) trata da atuação da agência de controle Governo e Lei (Skinner 1953/2003). Portanto, observa-se que esta produção é a única que discute, inicialmente, o quanto as agências de controle estão engajadas/envolvidas com a população LGBT. Não obstante, pode-se pensar a necessidade de ampliar a discussão, envolvendo também a Educação, a Psicoterapia e as demais agências.

\section{Considerações Finais}

Apesar das dissertações que envolvem Análise do Comportamento e a população LGBT aparentarem estar aumentando, sobretudo nesta última década, ainda não é possível, infelizmente, afirmar que a temática esteja consolidada. A maioria das produções recuperadas encontram-se a respeito da LGBTfobia (Fazzano, 2014; Devides, 2018; Teixeira, 2019), tendo principalmente seu foco em descrever o fenômeno da violência, não implicando em aprofundamento sobre as consequências das agressões para a vítima e nem sobre possíveis intervenções que poderiam ser feitas junto a essa população. Desta forma, espera-se que futuros estudos venham a preencher esta lacuna no conhecimento.

Não obstante, os estudos também não focam em possíveis intervenções que a Análise do Comportamento poderia promover no combate ao preconceito a esta população. Ainda que haja estudos analítico comportamentais que proponham intervenções em outras formas de violência, como o 
bullying (Williams, 2006; Valle, Stelko-Pereira, Sá e Williams, 2015), violência contra mulher (Cassado, Gallo e Williams, 2003; Williams e Pinheiro, 2006), violência contra criança (Prada, Williams, Weber, 2007) e mais recentemente o preconceito racial (Mizael e de Rose, 2017; Mizael e Sampaio, 2019), a população LGBT permanece ainda esquecida. Resta, então, questionar quais as variáveis que levaram os analistas do comportamento a, por tanto tempo, negligenciar temáticas relacionadas a esta população.

Ainda que não se possa responder a este questionamento tão prontamente, uma possibilidade para iniciar a resposta a isso se dá pelas publicações na área. Como observado neste levantamento, nota-se que, possivelmente, a maior concentração da temática está nas produções da pós-graduação, sobretudo ao comparar os resultados apresentados por Mizael (2018). Vale ressaltar que esta hipótese é válida somente ao comparar com o trabalho citado, uma vez que esta publicação é a mais recente que sintetiza os artigos da área, podendo novos artigos terem sido publicados após 2018. Seria interessante, então, averiguar junto aos autores, os motivos pelos quais não houveram publicações de artigos, atentando-se principalmente a receptividade da área, o que poderia ser uma possibilidade futura de estudos.

A respeito das limitações do estudo, destaca-se que a metodologia utilizada não garante acesso a eventuais produções que foram finalizadas e depositadas, mas não publicadas ou disponibilizadas on-line nas plataformas dos programas, sendo possível que mais produções de Análise do Comportamento sobre a população LGBT tenham ocorrido. Embora não se possa saber os motivos para esta não disponibilização, pode-se destacar que isto acarreta em perda para a comunidade acadêmica, sobretudo no desenvolvimento da ciência comportamental. Também vale destacar que a presente revisão sistemática realiza um recorte estático das produções. Possíveis pesquisas que estavam sendo realizadas, mas não foram finalizadas durante o período da coleta também não apareceram nos resultados. Ademais, pode ser que futuros estudos ocorram, sendo necessário ampliar esta revisão.

Apesar dessas limitações, é promissor observar que as produções sobre a população LGBT encontram-se, ainda que timidamente, crescendo na
Análise do Comportamento, pois mostra o quanto a Análise do Comportamento está ficando atenta a questões sociais contemporâneas e como isso pode contribuir para a sobrevivência dessa cultura científica. Espera-se que, no futuro, as produções analítico-comportamentais sobre a população LGBT continuem a aumentar, promovendo intervenções em saúde, segurança e outras áreas, combatendo o preconceito a esta população, modificando assim a cultura vigente.

\section{Referências}

Bento, B. (2006). A reinvenção do corpo: sexualidade e gênero na experiência transexual. Rio de Janeiro: Garamond

Butler, G. E., McKie, M., \& Ratcliffe, S. G. (1990). The cyclical nature of prepubertal growth. Annals of Human Biology, 17(3), 177-198. doi: 10.1080/03014469000000952

Butler, J. (2004). Undoing Gender. New York: Routledge.

Cassado, D. C.; Gallo, A. E.; Williams, L.C.A. (2003) Transtorno de Estresse Pós-Traumático em mulheres vítimas de violência doméstica: Um estudo piloto. Perfil \& Vertentes, 15(1), 99-108.

Conselho Federal de Psicologia (1999). Resolução $n^{\circ} 001$, de 22 de março de 1999: Estabelece normas de atuação para os psicólogos em relação à questão da orientação sexual. Brasília, DF: Conselho Federal de Psicologia.

Conselho Federal de Psicologia (1999). Resolução $n^{\circ} 001$, de 29 de janeiro de 2018: Estabelece normas de atuação para as psicólogas e os psicólogos em relação às pessoas transexuais e travestis. Brasília, DF: Conselho Federal de Psicologia.

Coppen, A. J. (1959). Body-build of male homosexuals. British Medical Journal, 2(5164), 14431445. DOI: 10.1136/bmj.2.5164.1443

Davison, K., Brierley, H., \& Smith, C. (1971). A male monozygotic twinship discordant for homosexuality: A repertory grid study. The British Journal of Psychiatry, 118(547), 675-682.

de Carvalho, M. R. A.; da Silveira, J. M; Dittrich, A. (2011). Tratamento dado ao tema "homossexualidade" em artigos do Journal of Applied Behavior Analysis: uma revisão crítica. Revista 
Brasileira de Análise do Comportamento, 7, 72-81. DOI: http://dx.doi.org/10.18542/rebac. v7i2.1451

Devides, M. B. C. (2018). A violência contra travestis e transexuais mulheres a partir de uma perspectiva analítico-comportamental. Dissertação de Mestrado, Programa de Pós Graduação em Análise do Comportamento, Departamento de Psicologia Geral e Análise do Comportamento, Universidade Estadual de Londrina, Londrina, PR, Brasil.

Fazzano, L. H. \& Gallo, A. E. (2015). Uma análise da homofobia sob a perspectiva da análise do comportamento. Temas em Psicologia, 22(3), 535-545. DOI: http://dx.doi.org/10.9788/ TP2015.3-02

Fazzano, L. H. (2014). Análise do fenômeno da homofobia: identificando contingências envolvidas. Dissertação de Mestrado, Programa de PósGraduação em Análise do Comportamento, Departamento de Psicologia Geral e Análise do Comportamento, Universidade Estadual de Londrina, Londrina, PR, Brasil.

Fernandes, M. (2018). Ações Lésbicas. In: James N. Green, Renan Quinalha, Márcio Caetano, Marisa Fernandes (Orgs). História do Movimento LGBT no Brasil (1a ed., Cap. 6, pp. 91-120). São Paulo: Alameda

Glenn, S. S. (1989). Verbal behavior and cultural practices. Behavior Analysis and Social Action, 7, 10-15.

Kinsey, A.C.; Pomeroy, W.B.; Matin, C.E. (1948). Sexual Behavior in the Human Male. Philadelphia: W.B. Saunders Company

Lima Neto, J. M. (2019). Riscos, vulnerabilidade e HIV/Aids entre homens que fazem sexo com homens: uma análise verbal. Dissertação de Mestrado, Programa de Pós-Graduados em Psicologia Experimental: Análise do Comportamento, Pontifícia Universidade Católica de São Paulo, São Paulo, SP, Brasil.

Malott, R. W. (1996). A behavior-analytic view of sexuality, transsexuality, homosexuality, and heterosexuality. Behavior and Social Issues, 6(2), 127-140

Menezes, A. B. (2005). Análise da investigação dos determinantes do comportamento homossexual humano. Dissertação de Mestrado, Programa de Pós-Graduação em Teoria e Pesquisa do Comportamento, Departamento de Psicologia Experimental, Universidade Federal do Pará Belém do Pará, PA, Brasil.

Ministério da Saúde. (2013). Política Nacional de Saúde Integral de Lésbicas, Gays, Bissexuais, Travestis e Transexuais ( $1^{\text {a }}$ edição, $1^{\text {a }}$ reimpressão). Secretaria de Gestão Estratégica e Participativa. Departamento de Apoio à Gestão Participativa. Brasília, DF: Ministério da Saúde. Recuperado de <https://bvsms.saude.gov.br/ bvs/publicacoes/politica_nacional_saude_lesbicas_gays.pdf $\mid>$

Mizael, T .M. \& de Rose, J. C. (2017). Análise do Comportamento e preconceito racial: possibilidade de interpretação e desafios. Acta comportamentalia, v. 25, 3, pp. 365-377.

Mizael, T .M. \& Sampaio, A. A. S. (2019). Racismo institucional: Aspectos comportamentais e culturais da abordagem policial. Acta comportamentalia, v. 25, 3, pp. 365-377.

Mizael, T. M. (2018) Perspectivas analítico-comportamentais sobre a homossexualidade: análise da produção cientifica. Perspectivas em Análise do Comportamento, 9(1), p 15-28. DOI: https://doi.org/10.18761/PAC.2017.011

Oliveira, J. A. de (2006). Os efeitos de episódios aversivos sobre a pessoa do terapeuta: uma exploração da relação terapêutica. Dissertação de Mestrado. Mestrado em Ciências Humanas Universidade Católica de Goiás

Paul, J. P. (1993). Childhood cross-gender behavior and adult homosexuality: The resurgence of biological models of sexuality. Journal of Homosexuality, 24(3-4), 41-54. DOI: https:// doi.org/10.1300/J082v24n03_03

Pedrosa, J. B. (2009). Característica Comportamental e Gênero. In: Vieira, Tereza Rodrigues.; Paiva, Luiz Airton S. (Orgs.). Identidade Sexual e Transexulidade. São Paulo: Roca.

Prada, C.G.; Williams, L.C.A. \& Weber, L.N.D. (2007). Abrigos para crianças vítimas de violência doméstica: funcionamento relatado pelas crianças e dirigentes. Psicologia: Teoria e Prática, 9,(2), 14-25.

Ruiz, M. R. (2003) Inconspicuous sources of behavior control: the case of gendered practices. 
The behavior analyst today, v. 4 (1), 12-16. DOI: $10.1037 / \mathrm{h} 0100005$

Saffioti, H. I. B. (2004). Gênero, Patriarcado, Violência. São Paulo: Fundação Perseu Abramo.

Scott, J. W. (1986). Gender: a useful category of historical analysis. The American Historical Review, 91(5), 1053-1075. doi: 10.2307/1864376

Secretaria da Justiça e da Defesa da Cidadania. (2018). Diversidade Sexual e a Cidadania LGBT ( $3^{a}$ edição). Coordenação de Políticas para a Diversidade Sexual. São Paulo, SP: Secretaria da Justiça e da Defesa da Cidadania. Recuperado de <http://justica.sp.gov.br/ wp-content/uploads/2017/07/Cartilha-3aEdi\%C3\%A7\%C3\%A3o-Final.pdf>

Simonassi, L. E., \& Cameschi, C. E. (2003). O episódio verbal e a análise de comportamentos verbais privados. Revista Brasileira de Terapia Comportamental e Cognitiva, 5(2), 105-119. DOI: https://doi.org/10.31505/rbtcc.v5i2.75

Skinner, B. F. (1978). O comportamento verbal. São Paulo: Cultrix -EDUSP. (Original publicado em 1957).

Skinner, B. F. (1990). Can psychology be a science of mind? American psychologist, 45(11), 12061210

Skinner, B. F. (2003). Ciência e Comportamento Humano. Porto Alegre: Artmed (Original publicado em 1953)

Teixeira, R. dos S. (2019). Criminalização da LGBTfobia: Uma análise comportamental de Projetos de Lei. Dissertação de Mestrado, Programa de Pós-Graduação em Psicologia do Desenvolvimento e Aprendizagem, Universidade Estadual Paulista "Júlio de Mesquita Filho, Bauru, SP, Brasil.

Valle, J. E., Stelko-Pereira, A. C., Sá, L. G. C. \& Williams, L. C. A. (2015). Bullying, vitimização por funcionários e depressão: Relações com o engajamento escolar. Revista Psicologia Escolar e Educacional, 19(3), 463-473. DOI: 10.1590/2175-3539/2015/0193872.

Vieira, M. de F. J. de A. (2007). Campo e função da auto-revelação do terapeuta no relacionamento terapêutico - a vivência do terapeuta. Dissertação de Mestrado, Mestrado em Psicologia. Universidade Católica de Goiás

Williams, L.C.A. (2006). Book review. Child
Victimization: Maltreatment, Bullying and Dating Violence, Prevention and Intervention. Child Abuse \& Neglect, 30, (4), 437-440.

Williams, L.C.A. e Pinheiro, F.M.F. (2006). Efeitos da denúncia da mulher na reincidência da violência física do parceiro. Revista Brasileira de Ciências Criminais, 63, 309-332.

World Health Organization (2018). WHO realeases new International Classification of Diseases (ICD 11). Recuperado de <https://www.who. int/news-room/detail/18-06-2018-who-releases-new-international-classification-of-diseases(icd-11)>

\section{Informações do Artigo}

Histórico do artigo:

Submetido em: 22/01/2020

Primeira decisão editorial: 20/07/2020

Aceito em: 31/07/2020

Editor associado: Táhcita Medrado Mizael 